Representaciones de la lengua portuguesa en la Argentina: la biblioteca de autores brasileños traducidos al castellano | 519

\title{
REPRESENTACIONES DE LA LENGUA PORTUGUESA EN LA ARGENTINA: LA BIBLIOTECA DE AUTORES BRASILEÑOS TRADUCIDOS AL CASTELLANO
}

\section{REPRESENTACÕES DA LÍNGUA PORTUGUESA NA ARGENTINA: A BIBLIOTECA DE AUTORES BRASILEÑOS TRADUCIDOS AL CASTELLANO}

RESUMEN: Este estudio analiza las representaciones sobre el portugués en los principales textos y paratextos que conforman la Biblioteca de Autores Brasileños Traducidos al Castellano, publicada por el gobierno argentino entre 1939 y 1943. La supremacía de una "diplomacia del intelecto" en la Biblioteca de Autores Brasileños Traducidos al Castellano, tiñe el discurso referido al Brasil, al portugués y sus culturas y es el resultado de una perspectiva liberal y "mitrista" de apertura integradora con respecto al Brasil. Es la impronta de la Academia Nacional de la Historia presidida por Ricardo Levene. Se podría decir que un sector del campo intelectual se conforma con el objetivo de estudiar y divulgar la cultura brasileña en el marco de una política de mejoramiento de las relaciones bilaterales, de un mayor conocimiento del país vecino e del incremento del intercambio de bienes culturales.

Palabras clave: Representaciones lingüísticas; estatuto formal e informal de lengua; mediación cultural; campo intelectual.

RESUMO: Este estudo analisa as representações sobre o português nos principais textos e paratextos que conformam a Biblioteca de Autores Brasileños Traducidos al Castellano, publicada pelo governo argentino entre 1939 e 1943. A supremacia de uma "diplomacia do intelecto" na Biblioteca de Autores Brasileños Traducidos al Castellano, tinge o discurso referido ao Brasil, ao português e suas culturas e é o resultado de uma perspectiva liberal e "mitrista" de abertura integradora no tocante ao

225 Professor adjunto do Departamento de Línguas Modernas da Faculdade de Filosofia e Letras da Universidade de Buenos Aires-UBA e da Universidade Nacional de Luján-UNLU, Argentina. 
Brasil. Leva a marca ideológica da Academia Nacional de la Historia presidida pelo historiador Ricardo Levene. É possível dizer que um setor do campo intelectual se organiza com o objetivo de estudar e divulgar a cultura brasileira no contexto de uma política de melhoramento das relações bilaterais, de um conhecimento mais profundo do país vizinho e do incremento do intercâmbio de bens culturais.

Palavras-chave: Representações linguísticas; estatuto formal e informal de língua; mediação cultural; campo intelectual.

8 de Dezembro de 1889. Apoz um longo periodo de desconfianças, A República Argentina e os Estados Unidos do Brazil sellam o pacto de uma franca e impertubavel amizade. $^{226}$

\section{Introducción}

Nuestro epígrafe acompaña, originalmente, el grabado de tapa de la Revista Illustrada de Angelo Agostini, fechada en Rio de Janeiro el 14 de diciembre de 1889. El diseño, de autoría de Pereira Neto, presenta en el centro, sobre un altar, el escudo argentino flanqueado por dos mujeres, representaciones alegóricas de la república, que se estrechan las manos en el interior del escudo. Cada una porta su bandera nacional, la República Argentina, a la izquierda y la República Brasileña, a la derecha. Guirnaldas de flores y otras tantas desparramadas por el suelo acompañan las miradas francas que se dirigen mutuamente. ¿Se hablan? ¿En qué idioma?

Desde mediados de los años ochenta, la enseñanza de portugués en la Argentina, tanto oficial como privada, se ha relacionado de manera estrecha, con el proceso de integración económica conocido como Mercosur. Se trata, junto a Uruguay, Chile y Paraguay, de una situación completamente singular en el contexto mundial de enseñanza de portugués. En la Argentina y en los países del Cono Sur, el acelerado proceso de integración económica generado a partir de 1991 con la firma del Tratado de Asunción, ha valorizado el aprendizaje del portugués en el imaginario colectivo de manera positiva -hasta ese entonces una lengua considerada "exótica". Gracias a esa coyuntura favorable, los profesores de portugués han experimentado un aumento notable en la demanda

${ }^{226}$ Cf. Carvalho (1997), p. 124. 
Representaciones de la lengua portuguesa en la Argentina: la biblioteca de autores brasileños traducidos al castellano | 521

profesional y el proprio tema de la enseñanza del portugués consigue, a pesar de los vaivenes circunstanciales de la política y la economía, un lugar destacado en la agenda de discusión académica. No obstante, un siglo después de aquella imagen alegórica de aproximación entre los pueblos, en el marco de las discusiones sobre la inclusión de la lengua portuguesa como disciplina en los planes de estudio de la educación pública en la Argentina, apuntaban Arnoux y Bein (1999, p. 15): "Hoy su consideración refleja las tensiones entre la constitución de la integración latinoamericana y la inserción del país en el mundo globalizado, como lo muestran la importancia que se otorga discursivamente pero no en la práctica al portugués". 227

Este florecimiento y relativa expansión de la enseñanza del portugués en la Argentina no debería encubrir, por lo tanto, una realidad cultural compleja, que no está libre de prejuicios y que debería ser tenida en cuenta, especialmente en lo que respecta a la enseñanza oficial. En este sentido, Amaral (1995) se refirió a aquellas ideas preconcebidas que actuaron en contra del desarrollo de la lengua portuguesa en el medio nacional, especialmente, al valor relativo que la sociedad argentina había atribuido tradicionalmente al portugués:

O pouco interesse pelo português radicava, essencialmente, nas escassas possibilidades de trabalho com essa língua que o mercado oferecia, na ideia, aliás errada, de que um falante do castelhano domina facilmente a comunicação em português e, finalmente, num imaginário da língua portuguesa que se associava a uma língua de pobres e incultos - não esqueçamos a rivalidade existente entre a Argentina e o Brasil, que levou muitas vezes os argentinos, porque possuidores de uma sociedade socialmente mais equilibrada e de uma importante metrópole cultural, Buenos Aires, a menosprezar os seus vizinhos. (AMARAL, 1995, p. 130)

Como contrapartida, hacia 1935, sin embargo, había comenzado ya un temprano proceso de paulatina oficialización e incorporación del

227 Sobre el desarrollo de la enseñanza de la lengua portuguesa en la Argentina con posterioridad al acuerdo Mercosur consultar: Saavedra (2009), Contursi (2012) y Bugel (2012). 
portugués como lengua extranjera en la enseñanza argentina. El acontecimiento más importante fue el inicio del curso para Profesores de Portugués y Literatura Brasileña en el Instituto Nacional del Profesorado Secundario de la Capital de la República Argentina (hoy llamado Instituto Superior del Profesorado "Dr. Joaquín V. González"). Al mismo tiempo, la Escuela Normal de Lenguas Vivas de la Ciudad de Buenos Aires organizó, por entonces, un curso libre de portugués. Asimismo, poco tiempo antes, a partir de 1932, el Presidente del Consejo Nacional de Educación, el Dr. Ramón J. Cárcano (posteriormente embajador en Rio de Janeiro), promovió cursos de portugués en escuelas primarias para adultos de la Capital Federal. Finalmente, la Ley 12.766, sancionada en 1942, confirió al portugués el carácter de opcional para los alumnos del último año de la escuela secundaria y propició la formación de profesores de portugués. Estos acontecimientos político-educativos estuvieron motivados por el notable acercamiento entre la Argentina y el Brasil, luego del viaje del Presidente Agustín P. Justo en 1932 a Rio de Janeiro; y, recíprocamente, por la llegada a Buenos Aires, en 1935, del Presidente de los Estados Unidos del Brasil, Dr. Getúlio Vargas, en visita oficial a la Argentina para los festejos del 25 de mayo - fecha en la que conmemora el primer gobierno patrio en ese país. Jorge Amado, que en ese entonces formó parte de la comitiva presidencial brasileña, como enviado del diario A Manhã, órgano de la Aliança Nacional Libertadora, recuerda:

Aquella vez (se trataba del viaje del Presidente de la República del Brasil al pueblo y a las autoridades argentinas) todo era Brasil en Buenos Aires y la impresión que daría a un turista inglés o japonés, que en esa ocasión pasara por la capital de la Argentina, era la de una ciudad que cultivaba sobre todo a los brasileños. Principalmente la fisonomía intelectual de Buenos Aires parecía exactamente ésa: la de una ciudad que sólo se interesaba por las cosas del país vecino. Los diarios sólo hablaban del Brasil, su pasado, su presente, su gran futuro, se leía de todo en relación al pueblo brasileño, en la calle todos querían informaciones sobre la vida de la nación amiga. Había realmente, en esa ocasión, una inmensa curiosidad por el Brasil. La excursión presidencial creó en el ambiente de fiestas y más allá de ese ambiente, en las calles y el pueblo, enormes ganas de saber de las tierras que se extendían al norte y del pueblo que las habitaba. Los diarios aparecían 
Representaciones de la lengua portuguesa en la Argentina: la biblioteca de autores brasileños traducidos al castellano | 523 abarrotados de noticias, incluso de datos estadísticos. Sólo la literatura no apareció en libros traducidos. O mejor dicho, no dejó de aparecer pues en aquella ocasión surgió la traducción de uno de los libros de cuentos de Monteiro Lobato, lo cual ya era una victoria para nuestra literatura pues se trataba de un libro del más grande cuentista del país. (AMADO, p. 71)

Es indudable que este rico movimiento de carácter coyuntural es la emergencia de un imaginario de más largo alcance en términos sociales, culturales e ideológicos y que ha dejado signos discursivos y textuales relevantes (convergentes y contradictorios), que explican la inflexión educativa e iluminan sobre su propia legitimación. ¿Dónde encontrar los trazos de las condiciones de posibilidad de una lengua extranjera en el imaginario de un pueblo? ¿Cómo apartar esos puntos clave, del entramado cultural de una época, sin separarlos ni dañar el tejido sino, apenas, levantar sutilmente las hebras constitutivas que suenan o hacen vibrar la lengua del vecino? ¿Cómo habla el vecino? En viaje hacia el Brasil por el río Paraná, mientras se acerca a la frontera y divisa los primeros habitantes, apunta Oliver (1982, p. 45): "Hablarán ya el portugués (...) o todavía el castellano?"

En la búsqueda de un imaginario argentino sobre el portugués es preciso relevar no solo la documentación oficial sobre la enseñanza de lenguas extranjeras sino la masa de textos que hablan del Brasil o de cómo el Brasil(eño) en la Argentina habla y es hablado. En este sentido, a partir de los años treinta, se produce un notable incremento de la divulgación de productos artísticos de expresión portuguesa en la prensa y el libro de edición argentina. La extraordinaria labor de traductor y de editor de Benjamín de Garay y la concreción de la Biblioteca de Autores Brasileños Traducidos al Castellano, del Ministerio de Justicia e Instrucción Pública, idea del Dr. Ricardo Levene, a partir de 1937, son algunos ejemplos de la emergencia de un mercado cultural acorde con el incipiente proceso de legitimación del portugués entre los argentinos.

La importancia de este proceso está, indudablemente, relacionado con la dinámica histórica, económica y geopolítica de la Argentina hacia los años treinta. ${ }^{228}$ Es en este contexto que resulta de interés analizar las

${ }^{228}$ V. Ciria (1986); Potash (1986); Rock (1989). Sobre la importancia del mercado editorial en esta etapa, ver Sorá (2003). Santos (2009) estudia las 
representaciones sociales que acompañaron, presidieron y condicionaron el proceso de implantación de la enseñanza del portugués como lengua extranjera y sus respectivas literaturas en el sistema educativo oficial argentino, en el período que se inicia en 1935 y que culmina en 1942.

Este estudio se propone focalizar una parte de ese denso entramado: las representaciones o el imaginario sobre el portugués y sus literaturas en los principales textos y paratextos que conforman la Biblioteca de Autores Brasileños Traducidos al Castellano.

\section{Imaginario: estatutos formal e informal de lengua}

Dentro del campo de la Didáctica de la lengua y la literatura, ocupa lugar importante el tema de las representaciones sociales del lenguaje. ${ }^{229}$ Estas establecen una estrecha relación entre el marco sociocultural y el marco educacional. Klett (1999, p. 315) se refiere, por ejemplo, al espacio psicosocial que ocupan las lenguas extranjeras en la Universidad de Buenos Aires: "El espacio físico reducido de las lenguas en la Universidad es, en realidad, consecuencia de otro espacio, el psicosocial, o, dicho de otro modo, de las representaciones de aquéllas que circulan en el imaginario colectivo". El problema tiene directa incidencia en la práctica docente: "...estas representaciones sobre las lenguas constituyen un substrato, un escenario, una tela de fondo que nutre e influencia a los docentes, a las autoridades, a los alumnos y a la comunidad". (KLETT, 1999, p. 317)

La incidencia de los factores sociales en la adopción y la circulación de una lengua extranjera, en nuestro caso, el portugués, el desarrollo de su estudio, los factores políticos, económicos, sociales y culturales, en términos discursivos, que a su vez inciden en el aprendizaje y la educación, son todos ellos factores que intervienen en la propia enseñanza de una lengua extranjera, la política educativa, la organización escolar, el diseño curricular y los métodos y sistemas pedagógicos. El análisis y la recuperación de ese imaginario lingüístico y educacional plantean, metodológicamente, problemas similares, a los que, en otro orden, encara Chartier (1999) desde la Historia cultural. Este campo se

relaciones culturales entre la Argentina y el Brasil y Canteros (2012) traza un recorrido histórico de la "lusofonía" en la Argentina.

229 Desde una perspectiva sociolingüística un panorama de la cuestión aparece en Matthey (1997). Sobre representaciones sociales seguimos a Doise y Palmonari (1986) y Jodelet (1986 y 1989). 
Representaciones de la lengua portuguesa en la Argentina: la biblioteca de autores brasileños traducidos al castellano | 525 caracteriza como aquel en el que se entrecruzan el análisis de textos, el estudio de los objetos impresos y la historia de las prácticas de lectura. Para nuestro objeto, la percepción de una lengua extranjera y una cultura asociada, nos sirve de inspiración el punto de vista de la recepción, la apropiación y la interpretación de textos que hablan en portugués y su cultura o que se refieren al portugués y su cultura o que prescriben una enseñanza o un aprendizaje, una difusión y una consideración especiales. Entre disposiciones oficiales, conferencias, libros de viaje, ensayos y reseñas circulan de manera diversa, diversamente apropiadas, imágenes y representaciones que se refieren al portugués ya sea en pleno reconocimiento o en el silencio de la negación. Se despliegan una serie de prácticas que modelan diversas representaciones y experiencias. Chartier (1999) enfoca el escrito impreso, su circulación y apropiación de manera que nos sugiere a nosotros pensar una lengua, inscripta en reglamentos y disposiciones pero también en traducciones o referencias, como diferenciadamente apropiable, asimétricamente valorada, en relación con los diversos lugares sociales. Este autor retoma la noción de representación social y los estudios de casos asimismo como la idea de mediación que nos parecen aplicables a nuestro caso y nos sugiere la pregunta sobre la relación entre representaciones del portugués y prácticas sociales asociadas a él.

Una reelaboración específica del concepto de imaginario, en tanto conjunto de representaciones sociales, aplicado al campo de la didáctica de las lenguas extranjeras, puede apreciarse en la distinción que Dabène (1994 y 1997) establece entre un "estatuto formal de lengua", el constituido por el conjunto de disposiciones oficiales con carácter jurídico, que rigen el empleo y la enseñanza de lenguas y un "estatuto informal de lengua”, esto es, el conjunto de imágenes presentes en el discurso ambiente, sostenido por los miembros del cuerpo social. Este último diseña la imagen de las lenguas en una sociedad. El estatuto informal incide en las decisiones de los actores sociales sobre el aprendizaje de lenguas extranjeras. Dice Dabène (1997, p. 20):

Il faut d'abord remarquer que ce statut n'est pas forcément toujours explicite: il peut arriver qu'il se manifeste de façon indirecte, biaisée: c'est le cas, pas exemple, de la décision prise par les parents en ce qui concerne le choix de la langue à apprendre par leur enfant lors de son parcours scolaire. Ce choix se fonde sur un certain nombre de 
raisons qui, pour n'être pas toujours exprimées ouvertement, n'en sont pas moins déterminantes.

Dabène (1997), a fin de analizar el estatuto informal de lengua, traza cinco parámetros, el "criterio económico", el "criterio social", el "criterio cultural", el "criterio epistémico" y el "criterio afectivo". ${ }^{230} \mathrm{El}$ criterio económico (o la utilidad) constituye, según Dabène (1997), una de las primeras razones de valorización de una lengua en la medida en que la difusión de una lengua está relacionada con el poder económico que confiere a sus hablantes. El criterio social y el criterio cultural confieren el prestigio de una lengua. Se aprecia una lengua en función del nivel social de sus hablantes y, en consecuencia, por las posibilidades sociales que puede ofrecer a los aprendices. Además, una lengua adquiere prestigio en términos culturales por el valor estético y literario de sus producciones escritas o la riqueza artística de otras manifestaciones intelectuales. También el pasado histórico más o menos glorioso influye en el nivel de prestigio de una lengua. Por otra parte, el criterio epistémico tiene que ver con las exigencias cognitivas que el aprendizaje de determinada lengua conlleva. En este sentido, la dificultad o la facilidad en relación con la proximidad a la lengua materna influye en una mayor o menor valoración. Por último, el criterio afectivo está relacionado con los lazos entre los pueblos y sus relaciones armónicas o conflictivas. La lengua del enemigo, por ejemplo, es siempre una lengua rechazada, desvalorizada y sospechosa. Esquematizamos estos conceptos en el Cuadro 1:

\begin{tabular}{|l|l|l|l|l|}
\hline \multicolumn{5}{|c|}{ CUADRO 1: ESTATUTO INFORMAL DE LENGUA } \\
\hline \multicolumn{5}{|c|}{ CRITERIOS DABÈNE (1994, p. 50-52) } \\
\hline UTILIDAD & \multicolumn{5}{|c|}{ PRESTIGIO } & FACILIDAD & $\begin{array}{l}\text { SIMPATÍA / } \\
\text { ANTIPATÍA }\end{array}$ \\
\hline \multicolumn{5}{|c|}{ CRITERIOS DABÈNE ( 1997, p. 21) } \\
\hline ECONÓMICO & SOCIAL & CULTURAL & EPISTÉMICO & AFECTIVO \\
\hline $\begin{array}{l}\text { "... une des } \\
\text { premières } \\
\text { raisons de } \\
\text { valorisation } \\
\text { d'une langue } \\
\text { est liée à l'accès }\end{array}$ & $\begin{array}{l}\text { "... une langue } \\
\text { est également } \\
\text { appréciée en } \\
\text { fonction du } \\
\text { niveau social } \\
\text { de ses }\end{array}$ & $\begin{array}{l}\text { ".. chaque } \\
\text { langue se voit } \\
\text { affecter ce que } \\
\text { nous } \\
\text { appellerions } \\
\text { un indice de }\end{array}$ & $\begin{array}{l}\text { "... une langue également } \\
\text { un objet de } \\
\text { savoir, dont la } \\
\text { maitrise } \\
\text { comporte en }\end{array}$ & $\begin{array}{l}\text { tous ces } \\
\text { critères, il } \\
\text { existe à } \\
\text { l'égard de } \\
\text { certaines }\end{array}$ \\
\hline
\end{tabular}

230 Dabène (1994) distinguía apenas cuatro criterios: la utilidad, la facilidad, el prestigio y la simpatía o antipatía. 
Representaciones de la lengua portuguesa en la Argentina: la biblioteca de autores brasileños traducidos al castellano | 527

\begin{tabular}{|c|c|c|c|c|}
\hline $\begin{array}{l}\text { quelle offre ou } \\
\text { non au monde } \\
\text { du travail. } \\
\text { Dans bien de } \\
\text { cas, la diffusion } \\
\text { d'une langue } \\
\text { est liée au } \\
\text { pouvoir } \\
\text { économique } \\
\text { qu'elle confère } \\
\text { à ses locuteurs." }\end{array}$ & $\begin{array}{l}\text { locuteurs, et } \\
\text { par } \\
\text { conséquent, } \\
\text { des } \\
\text { possibilités de } \\
\text { promotion, } \\
\text { d'ascension } \\
\text { sociale qu'elle } \\
\text { parait ouvrir à } \\
\text { ceux qui } \\
\text { entreprennent } \\
\text { son } \\
\text { apprentissage." }\end{array}$ & $\begin{array}{l}\text { prestige, qui } \\
\text { est le fruit de } \\
\text { la richesse } \\
\text { culturelle } \\
\text { dont elle est } \\
\text { porteuse mais } \\
\text { également de } \\
\text { sa propre } \\
\text { valeur } \\
\text { esthétique. } \\
\text { Cette richesse } \\
\text { culturelle } \\
\text { s'exprime bien } \\
\text { entendu par } \\
\text { la littérature } \\
\text { mais aussi } \\
\text { sous d'autres } \\
\text { formes } \\
\text { artistiques. } \\
\text { Elle peut être } \\
\text { liée à un passé } \\
\text { historique } \\
\text { glorieux ou } \\
\text { simplement } \\
\text { très ancien..." }\end{array}$ & $\begin{array}{l}\text { elle-même une } \\
\text { certaine valeur } \\
\text { éducative. } \\
\text { Cette valeur } \\
\text { est appréciée } \\
\text { en fonction } \\
\text { des exigences } \\
\text { cognitives que } \\
\text { l'on attache à } \\
\text { son } \\
\text { apprentissage. } \\
\text { D'où une } \\
\text { tendance bien } \\
\text { ancrée à } \\
\text { mesurer ces } \\
\text { exigences à } \\
\text { l'aune des } \\
\text { difficultés } \\
\text { rencontrées } \\
\text { par } \\
\text { l'apprenant, } \\
\text { lesquelles } \\
\text { relèvent, la } \\
\text { plupart du } \\
\text { temps du } \\
\text { domaine de la } \\
\text { morphologie, } \\
\text { phonétique ou } \\
\text { syntaxique. (...) } \\
\text { Dans cette } \\
\text { perspective, } \\
\text { une langue } \\
\text { jugée proche, } \\
\text { donc facile, est } \\
\text { quelque peu } \\
\text { dévalorisée." }\end{array}$ & $\begin{array}{l}\text { langues des } \\
\text { préjugés } \\
\text { favorables ou } \\
\text { défavorables } \\
\text { qui tiennent } \\
\text { aux aléas de } \\
\text { l'histoire, à } \\
\text { leur } \\
\text { émergence } \\
\text { sur la scène } \\
\text { internationale } \\
\text { et aux } \\
\text { relations } \\
\text { harmonieuses } \\
\text { ou } \\
\text { conflictuelles } \\
\text { entre les pays } \\
\text { où on les } \\
\text { parle." }\end{array}$ \\
\hline
\end{tabular}

\section{La Biblioteca de Autores Brasileños Traducidos al Castellano}

La Biblioteca de Autores Brasileños Traducidos al Castellano tiene su origen en el decreto del 16 de julio de 1936 en cuyos considerandos expone, entre otros conceptos, el objetivo de "difundir el conocimiento de obras sintéticas para estrechar las relaciones amistosas intelectuales entre escritores y profesores de Brasil y Argentina". La Biblioteca se 
compone de ocho obras de tema histórico, político, cultural, memorialístico o antropológico:

- Pedro Calmon, Historia de la Civilización Brasileña;

- Oliveira Vianna, Evolución del Pueblo Brasileño;

- Euclides da Cunha, Los sertones;

- Alfonso Celso, El Emperador D. Pedro II;

- Ruy Barbosa, Conferencias y discursos;

- Rodrigo Octavio, Mis memorias de los otros;

- Gilberto Freyre, Casa-grande y senzala;

- Ronald de Carvalho, Pequeña historia de la literatura brasileña.

Es el resultado de una iniciativa argentina de más amplio alcance: la revisión de los textos de enseñanza media de la geografía e historia a cargo de la Comisión Revisora de la Enseñanza de la Historia y Geografía Americanas presidida por el Dr. Ricardo Levene, de la Academia Nacional de la Historia. ${ }^{231}$ Además de Levene, conforman el grupo de prologuistas los argentinos Rodolfo Rivarola, especialista en Derecho y Presidente del Instituto Cultural Argentino-Brasileño; Mariano de Vedia, literato, historiador y constitucionalista; Emilio Ravignani, historiador (y como de Vedia, miembro de la Academia Nacional de la Historia); Octavio Amadeo, también historiador y miembro de la Academia, prologuista de la biografía de Lugones sobre Roca; Ricardo Sáenz Hayes, crítico literario y autor de un ensayo titulado El Brasil moderno (1942); Rómulo Zabala, historiador, miembro de la Academia Nacional de la Historia; y el historiador brasileño, Max Fleiuss. Las traducciones estuvieron a cargo de Julio E. Payró, más tarde destacadísimo crítico de arte, y de Benjamín de Garay, periodista y editor de obras brasileñas,

${ }^{231}$ Las "Proposiciones de la Comisión Argentina para la Enseñanza de la Historia y Geografías Americanas" así como las "Normas de la Comisión Brasileña para la Enseñanza de la Historia y Geografía Americanas", del 6 de noviembre de 1935 y del 19 de mayo de 1936 respectivamente, se encuadran en el Convenio entre la República Argentina y la República de los Estados Unidos del Brasil para la revisión de los textos de enseñanza de historia y geografía firmado por los Ministros de Relaciones Exteriores Carlos Saavedra Lamas y A. de Mello Franco. Cf. Calmon (1937), p. 409 y ss. 
Representaciones de la lengua portuguesa en la Argentina: la biblioteca de autores brasileños traducidos al castellano | 529 ligado al diario La Prensa y a la editorial Claridad. ${ }^{232}$ En el cuadro siguiente exponemos los títulos de la colección y las referencias bibliográficas (Cuadro 2):

\begin{tabular}{|c|c|c|c|c|}
\hline \multicolumn{5}{|c|}{$\begin{array}{c}\text { CUADRO 2: BIBLIOTECA DE AUTORES BRASILEÑOS } \\
\text { TRADUCIDOS AL CASTELLANO }\end{array}$} \\
\hline VOLUMEN & AÑO & $\begin{array}{l}\text { AUTOR \& } \\
\text { TRADUCTOR }\end{array}$ & EDITOR & OBSERVACIONES \\
\hline $\begin{array}{l}\text { I. Historia } \\
\text { de la } \\
\text { Civilización } \\
\text { Brasileña }\end{array}$ & 1937 & $\begin{array}{l}\text { - Pedro } \\
\text { Calmon } \\
\text { - Julio E. } \\
\text { Payró }\end{array}$ & $\begin{array}{c}\text { Ministerio } \\
\text { de Justicia } \\
\text { e } \\
\text { Instrucción } \\
\text { Pública }\end{array}$ & $\begin{array}{c}\text { Prólogo de Ricardo } \\
\text { Levene }\end{array}$ \\
\hline $\begin{array}{c}\text { II. } \\
\text { Evolución } \\
\text { del Pueblo } \\
\text { Brasileño }\end{array}$ & 1937 & $\begin{array}{l}\text { - Oliveira } \\
\text { Vianna } \\
\text { - Julio E. } \\
\text { Payró }\end{array}$ & Idem & $\begin{array}{c}\text { Prólogo de Rodolfo } \\
\text { Rivarola }\end{array}$ \\
\hline $\begin{array}{l}\text { III y IV. Los } \\
\text { sertones }\end{array}$ & 1938 & $\begin{array}{l}\text { - Euclides da } \\
\text { Cunha } \\
\text { - Benjamín de } \\
\text { Garay }\end{array}$ & Idem & $\begin{array}{c}\text { Prólogo de Mariano } \\
\text { de Vedia }\end{array}$ \\
\hline $\begin{array}{c}\text { V. El } \\
\text { Emperador } \\
\text { D. Pedro II } \\
\text { y el Instituto } \\
\text { Histórico }\end{array}$ & 1939 & Alfonso Celso & Idem & $\begin{array}{l}\text { Prólogo de Max } \\
\text { Fleiuss / Palabras de } \\
\text { Ricardo Levene }\end{array}$ \\
\hline
\end{tabular}

${ }^{232}$ Benjamín Bertoli Garay nació en 1875. Colaboró asiduamente en la sección cultural del diario La Prensa y se desempeñó como editor y traductor de autores brasileños y portugueses. Introdujo en la Argentina a escritores los brasileños Monteiro Lobato y Graciliano Ramos, entre otros. Falleció en Buenos Aires a comienzos de 1943. Sobre la intensa trayectoria de Garay en el Brasil y en la Argentina, consultar: Leite (1996), De Luca (1999) y Ribeiro (2008). 


\begin{tabular}{|c|c|c|c|c|}
\hline $\begin{array}{c}\text { VI. } \\
\text { Conferencias } \\
\text { y discursos }\end{array}$ & 1939 & $\begin{array}{c}\text { - Ruy Barbosa } \\
\text { - Julio E. } \\
\text { Payró }\end{array}$ & Idem & $\begin{array}{c}\text { Prólogo de Emilio } \\
\text { Ravignani }\end{array}$ \\
\hline $\begin{array}{l}\text { VII. Mis } \\
\text { memorias de } \\
\text { los otros }\end{array}$ & 1940 & $\begin{array}{c}\text { - Rodrigo } \\
\text { Octavio de } \\
\text { Langaard } \\
\text { Menezes } \\
\text { - Benjamín de } \\
\text { Garay }\end{array}$ & Idem & $\begin{array}{c}\text { Prólogo de Octavio } \\
\text { Amadeo }\end{array}$ \\
\hline $\begin{array}{l}\text { VIII-IX. } \\
\text { Casa-grande } \\
\text { y senzala }\end{array}$ & 1942 & $\begin{array}{c}\text { - Gilberto } \\
\text { Freyre } \\
\text { - Benjamín de } \\
\text { Garay }\end{array}$ & Idem & $\begin{array}{l}\text { Prólogo de Ricardo } \\
\text { Sáenz Hayes / Carta } \\
\text { de Ricardo Levene a } \\
\text { Gilberto Freyre y } \\
\text { respuesta de este } \\
\text { aceptando la } \\
\text { publicación de Casa- } \\
\text { grande y senzala con } \\
\text { elogio a B. de Garay. }\end{array}$ \\
\hline $\begin{array}{c}\text { X. Pequeña } \\
\text { historia de la } \\
\text { literatura } \\
\text { brasileña }\end{array}$ & 1943 & $\begin{array}{l}\text { - Ronald de } \\
\text { Carvalho } \\
\text { - Julio E. } \\
\text { Payró }\end{array}$ & Idem & $\begin{array}{c}\text { Prólogo de Rómulo } \\
\text { Zabala }\end{array}$ \\
\hline
\end{tabular}

De este grupo "brasilófilo" se destacan, por el compromiso con este proyecto, dos personalidades, Ricardo Levene y Benjamín de Garay. De ellos resultan representativos del conjunto de especial interés, para los fines de este trabajo, el "Prólogo" que escribe Ricardo Levene a la Historia de la Civilización Brasileña (1937) de Pedro Calmon, volumen que abre la serie, y la nota de Benjamín de Garay, "Dos palabras del traductor", a propósito de Los sertones (1938) de Euclides da Cunha. ${ }^{233}$

${ }^{233}$ El "Prólogo" aparece también en Levene (1946), p. 257-62. Benjamín de Garay publica otra versión, más desarrollada de "Dos palabras del 
Representaciones de la lengua portuguesa en la Argentina: la biblioteca de autores brasileños traducidos al castellano | 531

Levene (1937) pone el acento en la relación diplomática entre el Brasil y la Argentina, en un recorrido histórico que ha superado viejas disputas y en una unión que se ha consolidado con las visitas presidenciales de Roca, Campos Salles, Justo y Vargas, pero que reconoce dos antecedentes significativos: el Ejército Grande de Urquiza para derrocar a Rosas y la guerra de la Triple Alianza. De lo cual ha brotado el gesto pionero, por parte de la Argentina, del reconocimiento de la República Brasileña apenas instaurado el nuevo régimen en 1889.

Destaca Levene (1937), también, los aspectos culturales de la Biblioteca en el contexto de un mejor entendimiento bilateral. En este sentido, el discurso americanista solo se circunscribe a la realidad brasileña. Hay en el discurso de historiador argentino un interesante matiz económico al poner en paralelo ambos países y dos de sus prohombres, Moreno y el Vizconde de Cayrú. Se produce el hecho significativo de que en el mismo año en que se publica en Buenos Aires la "Representación de los Hacendados y Labradores" (1809) también aparece traducida al portugués en el Brasil, por obra de Cayrú. "Tiene sentido simbólico este entendimiento espontáneo de dos grandes talentos", dice Levene. La circulación ideológica y cultural implica también un saludable intercambio comercial en el marco del modelo liberal. \}

Esquematizamos el pensamiento de Levene (1937) en base a los parámetros de Dabène (1997) en el siguiente cuadro:

\section{CUADRO 3: RICARDO LEVENE (1937) SEGÚN CRITERIOS DE DABÈNE (1997)}

\begin{tabular}{l|l} 
ECONÓMICO & $\begin{array}{l}\text { "La historia del Brasil y Argentina, están fundadas en } \\
\text { hechos que van jalonando su evolución fraterna ..." } \\
\text { "Me limito a sugerir la extensión de un tema de gran }\end{array}$
\end{tabular}

traductor" como "Prefacio del Traductor a la 2da. edición" en Garay (1942) p. 9-12. Benjamín de Garay es el responsable de una vasta labor de traductor, editor y prologuista de literatura brasileña en nuestro país, especialmente publicada por la editorial Claridad y en el diario La Prensa de Buenos Aires. Sobre las relaciones culturales entre intelectuales argentinos y brasileños en el período que consideramos, consultar el estudio de Diniz y Rangel (2016). 


\begin{tabular}{|l|l|}
\hline & significado para la paz, la cultura, la política y aun la \\
economía de América." \\
"En el momento histórico de la independencia \\
Argentina y del Brasil dos pensadores se asocian en la \\
lucha por la libertad comercial: Mariano Moreno, \\
publicista y pensador, apóstol de la Revolución de \\
Mayo y José da Silva Lisboa, Vizconde de Cayrú..."
\end{tabular}

En cuanto al más breve texto de Benjamín de Garay, que sirve de relieve al riguroso y arduo trabajo de traducción de Os sertões, tienen especial destaque tres de los criterios enunciados por Dabène (1997): el "criterio cultural", el "criterio afectivo" y el "criterio epistémico".

La relación afectiva de Benjamín Garay (correntino de nacimiento) con la lengua portuguesa se justifica por sus orígenes familiares (su padre fue un militar brasileño) y por su larga permanencia en São Paulo en las primeras dos décadas del siglo XX. En este sentido, Garay sería un 
Representaciones de la lengua portuguesa en la Argentina: la biblioteca de autores brasileños traducidos al castellano | 533 argentino culturalmente fronterizo; por otra parte, parece haber experimentado tres lenguas en contacto: el castellano, el guaraní y el portugués, según se infiere de la versión ampliada a la nota sobre Los sertones que da a conocer en la segunda edición, de editorial Claridad, en $1942 .^{234}$

Además de resaltar las particulares dificultades de traducción que le produjo un texto tan atípico y sorprendente como Os sertões, los juicios de Garay sobre la riqueza y la complejidad del portugués contrastan con la ausencia de mención a la lengua que se advierte en el texto de Levene (1937). Dice Garay sobre Los sertones: "... en una prosa única. Única no puramente por su estilo, sino también por su complexión lexicográfica..." La perspectiva de Garay se complementa con la de Levene, no obstante, en la medida en que resalta aspectos técnicos más específicamente ligados con la experiencia de la lengua. En el Cuadro 4 exponemos las principales apreciaciones de Garay sobre la lengua portuguesa tomando como referentes los parámetros de Dabène (1997):

\section{CUADRO 4: BENJAMÍN DE GARAY (1938) SEGÚN CRITERIOS DE DABÈNE (1997)}

\begin{tabular}{|l|l|}
\hline ECONÓMICO & \multicolumn{1}{|c|}{$\varnothing$} \\
\hline SOCIAL & \multicolumn{1}{|c|}{$\varnothing$} \\
\hline CULTURAL & $\begin{array}{l}\text { ".. un libro tan fuertemente original, tan exclusivo y } \\
\text { tan grande como Os Sertões, el más original y exclusivo, } \\
\text { brasileña de todos los tiempos." } \\
\text { "... el inimitable estilo euclidiano, alma y enjundia de } \\
\text { esta obra magistral..." } \\
\text { "... una obra de gran aliento, de ciencia y de arte, de } \\
\text { verdad y belleza, de análisis y justicia, realizado por un } \\
\text { genio en una prosa única. " } \\
\text { "... el esfuerzo que hemos realizado, (...) se justifica } \\
\text { solamente por el noble propósito que lo inspirara: el de } \\
\text { prestar a la cultura de nuestra América el servicio }\end{array}$ \\
\hline
\end{tabular}

234 En Pasero (2004) hacíamos uso del concepto de "sileno" para caracterizar la naturaleza del trabajo de aproximación e intercambio llevado a cabo por Benjamín de Garay como mediador cultural. 


\begin{tabular}{|c|c|}
\hline & $\begin{array}{l}\text { imponderable de señalar la existencia de un genio } \\
\text { americano, y de demostrarla en la exhibición de su } \\
\text { obra máxima." }\end{array}$ \\
\hline EPISTÉMICO & $\begin{array}{l}\text { "Hay, en general, dificultades de todo orden, } \\
\text { insalvables, a primera vista, en la versión correcta del } \\
\text { libro brasileño al castellano que hablamos los } \\
\text { argentinos. Y cuando se trata, como en el caso } \\
\text { presente, de un libro prócer, de una obra maestra a la } \\
\text { vez que de un documento histórico extraordinario, } \\
\text { claro está que la traducción ha de rayar también en lo } \\
\text { extraordinario en cuanto a las dificultades y peligros de } \\
\text { toda naturaleza que habrá que vencer." } \\
\text { "... en una prosa única. Única no puramente por su } \\
\text { estilo, sino también por su complexión lexicográfica, el } \\
\text { desconcertante vigor y el colorido enceguecedor de sus } \\
\text { imágenes, más la plenitud y la variedad de } \\
\text { conocimientos científicos que en él se han puesto al } \\
\text { servicio del genio literario." }\end{array}$ \\
\hline AFECTIVO & $\begin{array}{l}\text { "Solamente, en razón y por virtud de un compromiso } \\
\text { espiritual que tiene raíces tan hondas como jugosas: de } \\
\text { solidaridad, de amor y de gratitud, se ha podido hacer } \\
\text { frente a la tarea de traducir íntegramente, aunque sólo } \\
\text { sea en forma mediocre, un libro tan fuertemente } \\
\text { original..." }\end{array}$ \\
\hline
\end{tabular}

\section{Conclusiones}

De la aproximación provisoria a este complejo corpus que es la Biblioteca se podrían extraer las siguientes conclusiones:

a) La supremacía de una "diplomacia del intelecto" que tiñe el discurso referido al Brasil, al portugués y sus culturas es el resultado de una perspectiva liberal y "mitrista" de apertura integradora con respecto al Brasil cuyos antecedentes se remontan a la coalición que derrocó a Rosas. Es la impronta de la Academia Nacional de la Historia presidida por Levene. Se podría decir que un sector del campo intelectual se conforma alrededor del objetivo del estudio y la divulgación de las culturas de expresión portuguesa en el marco de una política de buenas relaciones, conocimiento del vecino e incremento del intercambio cultural. El campo intelectual es un terreno de disputa alrededor de un capital cultural y la 
Representaciones de la lengua portuguesa en la Argentina: la biblioteca de autores brasileños traducidos al castellano | 535 determinación de jerarquías. ${ }^{235}$ De este modo, las posiciones adoptadas por los intelectuales con respecto a su propia misión y responsabilidad debería ser analizada en relación con las otras fuerzas y relativamente consideradas en el seno del campo intelectual en cuestión, como piezas de fuerza en el tablero de las posiciones que se defienden. El sector liderado por Levene, estrechamente relacionado con la política oficial del Presidente Justo, realiza con la Biblioteca, a pesar de sus limitaciones, el reduccionismo histórico que encubre el objetivo de entender el Brasil, una suerte de operación cultural con el fin de modificar el estatuto informal de portugués en la Argentina conciliando "utilidad" y "prestigio". Resulta emblemático el párrafo que Benjamín de Garay le dedica en su texto sobre la traducción de Los sertones a Ricardo Levene. En ese elogio Garay destaca el carácter "americanista" de Levene y de descubridor de valores ocultos en la cultura brasileña: "Como buen cateador del oro puro que se esconde en la mentalidad de la gran nación vecina..."

b) Una perspectiva cultural destinada a entrelazar las elites intelectuales del Brasil y de la Argentina instaura, refleja y contribuye a moldear un "imaginario" en torno de la lengua portuguesa mediada por la experiencia de las grandes obras literarias del pensamiento. En la empresa cultural de la Biblioteca queda excluida la ficción porque sus objetivos son el conocimiento de una mentalidad colectiva en relación con el medio, los recursos económicos y el pasado histórico. La originalidad y la fuerza expresiva de los textos seleccionados los ubica en un canon de juristas e historiadores, lo que no oblitera un trasfondo de "las grandes obras de la literatura brasileña de todos los tiempos." Para el público argentino "... el esfuerzo que hemos realizado, apunta Garay, (...) se justifica solamente por el noble propósito que lo inspirara: el de prestar a la cultura de nuestra América el servicio imponderable de señalar la existencia de un genio americano, y de demostrarla en la exhibición de su obra máxima." El criterio afectivo, ligado indudablemente al dato autobiográfico, no obstante caracteriza la autoimagen de principal acercamiento a una lengua que todavía no puede parangonarse al francés.

${ }^{235}$ Para Bourdieu (1983, p. 23), los intelectuales no conforman una clase sino "... una fracción dominada de la clase dominante, que en razón de su posición estructuralmente ambigua está necesariamente obligada a mantener una relación ambivalente tanto con las fracciones dominantes de la clase dominante (los burgueses), como con las clases dominadas (el pueblo), y a hacerse una imagen ambigua de la propia función social". 
En palabras de Garay: "Solamente, en razón y por virtud de un compromiso espiritual que tiene raíces tan hondas como jugosas: de solidaridad, de amor y de gratitud..."

A la Profesora Estela Klett.

\section{BIBLIOGRAFÍA}

AMADO, J. Buenos Aires, capital de Hispanoamérica. In: ANTELO, R. Confluencia. Buenos Aires: Centro de Estudios Brasileños, 1982. (Versión original: Dom Casmurro, Rio de Janeiro, a. 2, n. 46-7, abr. 1938).

AMARAL, J. L. M. O português na Argentina. Revista Internacional de Lingua Portuguesa, Lisboa, v.14, pp. 128-31, 1995.

ARNOUX, E.; BEIN, R. (comp.). Prácticas y representaciones del lenguaje. Buenos Aires: Eudeba, 1999.

BOURDIEU, P. Campo del poder y campo intelectual. Buenos Aires: Folios, 1983.

BURGEL, T. O ensino das línguas do Mercosul. Aproximando-nos da maioridade (1991-2012). Latin American Research Review, v. 47, número especial, pp. 69-94, 2012. Disponible en: <http://lasa.international.pitt.edu/LARR/prot/fulltext/vol47noSI/ 47 SI_70-94_bugel.pdf $>$. Acceso: 9 jul 19.

CALMÓN, P. Historia de la Civilización Brasileña. Buenos Aires: Ministerio de Justicia e Instrucción Pública, 1937.

CANTEROS, A. Lusofonia ao sul: imigração e experiências culturais na Argentina em chave histórica. Platô, v. 1, n. 2, pp. 72-86, 2012.

CARVALHO, J. M. La formación de las almas. El imaginario de la República en el Brasil. Quilmes: Universidad Nacional de Quilmes, 1997. Disponible en: <https://issuu.com/platorevista/docs/praia-dez-2013-115paginas>. Acceso: 9 jul 19.

CHARTIER, R. El mundo como representación. Historia cultural: entre práctica y representación. Barcelona: Gedisa, 1999.

CIRIA, A. Partidos y poder en la Argentina moderna (1930-1946). Buenos Aires: Hyspamérica, 1986.

CONTURSI, M. E. Política y planificación lingüística en los primeros 10 años del Mercosur: el portugués en Argentina. Signos ELE, n. 6, pp. 1-25. Disponible en: https://p3.usal.edu.ar/index.php/ele/article/view/667/800>. Acceso: 9 jul 2019. 
Representaciones de la lengua portuguesa en la Argentina: la biblioteca de autores brasileños traducidos al castellano | 537

DABÈNE, L. Repères sociolinguistiques pour l'enseignement des langues. Paris: Hachette, 1994.

DABÈNE, L. L'image des langues et leur apprentissage. In: MATTHEY, M. (Coord.). Les langues e leurs images. Neuchâtel: Institut de Recherches et Documentation Pédagogiques, 1997.

DE LUCA, T. R. A Revista do Brasil: um diagnóstico para a (N)ação. São Paulo: Fundação Editora da UNESP, 1999.

DINIZ, D.; RANGEL, L. Intercambios y traducciones: Benjamín de Garay y Raúl Navarro / Newton Freitas y Lídia Besouchet. In: CROCE, M. (Dir.). Historia comparada de las literaturas argentina y brasileña: de la vanguardia a la caída de los gobiernos populistas. Villa María: Eduvim, 2016.

DOISE, W.; PALMONARI, A. L'étude des représentations sociales. Paris: Delachaux et Niestlé, 1986.

GARAY, B. Dos palabras del traductor. In: CUNHA, E. Los sertones (Os Sertões). Buenos Aires: Biblioteca de Autores Brasileños Traducidos al Castellano, 1938.

GARAY, B. Prefacio del traductor a la segunda edición. In: CUNHA, E. Los sertones. La tragedia del hombre derrotado por el medio. Trad. B. de Garay. Buenos Aires: Claridad, 1942.

JODELET, D. La representación social: fenómenos, concepto y teoría. In: MOSCOVICI, S. Psicología social II. Pensamiento y vida social, psicología social y problemas sociales. Barcelona: Paidós, 1986.

JODELET, D. Les représentations sociales. Paris: PUF, 1989.

KLETT, E. Políticas lingüísticas en la universidad: el difícil camino de Babel. In: AA. VV. Políticas lingüísticas para América Latina. Buenos Aires: Facultad de Filosofía y Letras de la Universidad de Buenos Aires, 1999.

LEITE, S. H. T. de A. Chapéus de palha, panamás, plumas, cartolas: a caricatura na literatura paulista (1900-1920). São Paulo: Fundação Editora da UNESP, 1996.

LEVENE, R. La cultura histórica y el sentimiento de la nacionalidad. 2a ed. Buenos Aires: Espasa-Calpe, 1946.

MATTHEY, M. (Org.). Les langues et leurs images. Neuchâtel, Institut de Recherches et Documentation Pédagogiques, 1997.

OLIVER, M. R. Imágenes del Brasil. In: ANTELO, R. Confluencia. Buenos Aires: Centro de Estudios Brasileños, 1982.

PASERO, C. A. Los límites de la lengua. Benjamín de Garay y la praxis de la traducción". In: Graphos (Universidade Federal de Paraíba) 6,2-1, pp. 95-100, 2004. 
POTASH, R. El ejército y la política en la Argentina I 1928-1945. De Yrigoyen a Perón. Buenos Aires: Hyspamérica, 1986.

RIBEIRO, M. P. G. Monteiro Lobato e a Argentina: mediações culturais. São Paulo: Universidad de São Paulo. Tesis de doctorado. Disponible en: <https:// www.teses.usp.br/teses/disponiveis/8/8145/tde-07102008171507/pt-br.php>. Acceso: 1 jul 19.

ROCK, D. Argentina 1516-1987. Desde la colonización española hasta Alfonsín. Buenos Aires: Alianza, 1989.

SANTOS, R. P. dos. Relações Brasil-Argentina: a cooperação cultural como instrumento de integração regional. In: Estudos Históricos, Rio de Janeiro, v. 22, n. 44, pp. 355-375, 2009. Disponible en: <http://www.scielo.br/scielo.php?pid=S0103. $21862009000200003 \&$ script=sci_abstract\&tlng=pt $>$. Acceso: 9 jul 19. SAVEDRA, M. M. Guimarães. O português no Mercosul. Cadernos de Letras da UFP, n. 39, pp. 175-184, 2009. Disponible en: <http://www.cadernosdeletras.uff.br/joomla/ images/stories/edicoes/39/artigo 10.pdf>. Acceso: 9 jul 19.

SORÁ, G. Traducir el Brasil. Una antropologia de la circulación internacional de ideas. Buenos Aires: Libros del Zozal, 2003.

Recebido em: 11/07/2019

Aceito em: 16/09/2019 